\title{
Cocaethylene Measurement
}

National Cancer Institute

\section{Source}

National Cancer Institute. Cocaethylene Measurement. NCI Thesaurus. Code C156510.

The determination of the amount of cocaethylene present in a sample. 